Cadernos Walter Benjamin 26

\title{
ESTADO DE EXCEÇÃO E VIOLÊNCIA PREGNANTE: UMA APOSTA DE HISTÓRIA A CONTRAPELO DO CONCEITO DE GEWALT EM WALTER BENJAMIN
}

\author{
Antonio Gasparetto Júnior \\ Pedro Ivo Dias Tanagino
}

\begin{abstract}
RESUMO
Nosso objetivo é sugerir uma reflexão contraintuitiva sobre o conceito de Gewalt ("violência"; "poder") em Walter Benjamin, em torno do tema do poder constituinte e do estado de exceção no Estado democrático de direito. Nosso método se inspira na proposta benjaminiana de uma história política da literatura feita a contrapelo, a partir da perspectiva de "história vista de baixo". As fontes deste estudo foram os textos de Benjamin: Para a Crítica da Violência (2013), de 1921, Origem do Drama Barroco Alemão (1984), escrito em 1925 e publicado em 1928, e a Tese VIII de Sobre o Conceito de História (2012), escrita entre 1939 e 1940, e trazida à notoriedade somente após a morte do autor.
\end{abstract}

Palavras-chave: Estado de Exceção. Poder. Violência. História. Walter Benjamin.

\section{STATE OF EXCEPTION AND PREGNANT VIOLENCE: A BET ON HISTORY AGAINST THE GRAIN ON THE CONCEPT OF GEWALT IN WALTER BENJAMIN}

\begin{abstract}
Our objective is to suggest a counter-intuitive reflection on the concept of Gewalt ("violence"; "power") in Walter Benjamin, around the theme of the constituent power and the state of exception in the democratic rule of law. Our method is inspired by Benjamin's proposal of a political history of literature brushed against the grain, from the perspective of a "history seen from below". The sources of this study were Benjamin's texts: For the Critique of Violence (2013), from 1921, Origin of the German Baroque Drama (1984), written in 1925 and published in 1928, and Thesis VIII of On the Concept of History (2012), written between 1939 and 1940, and brought to notoriety only after the author's death.
\end{abstract}

Keywords: State of Exception. Power. Violence. History. Walter Benjamin.

Pesquisador de pós-doutoramento na Universidade de São Paulo (USP) e Doutor em História pela Universidade Federal de Juiz de Fora (UFJF) com estágio de doutoramento na Université Paris IV - Sorbonne. Professor do Mestrado Profissional em Administração Pública (PROFIAP) da UFJF. Brasileiro, residente em Juiz de Fora (MG). E-mail: antonio.gasparetto@gmail.com Pesquisador em estágio de pós-doutoramento com a Bolsa PPGH-PUCSP/PNPD-CAPES. Número do Processo: 88887.373072/2019-00. Projeto: 88882.463217/2019-01 - Pontifícia Universidade Católica de São Paulo. Doutor em História pela Universidade Federal de Juiz de Fora (UFJF) com estágio de doutoramento no Instituto de Ciências Sociais da Universidade de Lisboa (ICS-UL). Brasileiro, residente em Juiz de Fora (MG). E-mail: pidtanagino@gmail.com 


\section{Pela história dos "vencidos"}

O interesse crescente nas últimas décadas pela obra do filósofo, crítico literário, ensaísta e tradutor Walter Benedix Schönflies Benjamin (1892-1940) o coloca como um dos mais eminentes historiadores da cultura do século XX. Benjamin nasceu em Berlim em 15 de julho de 1892, em uma família de origem judia e posição privilegiada na burguesia alemã. Sua trajetória como intelectual marxista, judeu e crítico do fascismo o fizeram ser perseguido pelo regime nazista e, provavelmente, decalcaram em sua obra os temas sobre a teoria do estado de exceção, do direito e da violência, a partir da perspectiva dos oprimidos. Suas reflexões sobre este tema influenciaram alguns dos principais estudiosos do estado de exceção que figuram hoje com centralidade nas ciências sociais, como Hannah Arendt (2012), Jacques Derrida (2018), Giorgio Agamben (2004), Achille Mbembe (2020), dentre outros.

Em suas investigações, Benjamin dedicou-se a vários campos de interesse, que refletem as mais diferentes influências de seu pensamento, que recebeu o reconhecimento acadêmico somente após sua morte. Sua origem judia contribuiu com a importância dada em seus estudos às relações entre religião e política, linguagem e mito na contemporaneidade. Um campo de interesse reforçado pela sua amizade com o filósofo judeu Gershom Scholem, um pesquisador da Cabala e do simbolismo na arte judaica, tema que marca com hermetismo e esoterismo os escritos da juventude de Benjamin. Mas não se pode depreender uma clivagem estanque entre as "fases" do autor, a dimensão metafísica elaborada em seu pensamento nessa época se fez presente ao longo de toda a sua obra (GAGNEBIN, 2013, 7-9).

A sua aproximação com os ideais socialistas foi ainda na adolescência, nos movimentos estudantis e sob a inspiração do teatro de Bertold Brecht, de quem se tornou um grande amigo. A amizade com o filósofo marxista Ernst Bloch, firmada em 1919, o conduziu ao estudo de Georg Lukács e,

Pesquisador de pós-doutoramento na Universidade de São Paulo (USP) e Doutor em História pela Universidade Federal de Juiz de Fora (UFJF) com estágio de doutoramento na Université Paris IV - Sorbonne. Professor do Mestrado Profissional em Administração Pública (PROFIAP) da UFJF. Brasileiro, residente em Juiz de Fora (MG). E-mail: antonio.gasparetto@gmail.com

Pesquisador em estágio de pós-doutoramento com a Bolsa PPGH-PUCSP/PNPD-CAPES.

Número do Processo: 88887.373072/2019-00. Projeto: 88882.463217/2019-01 - Pontifícia Universidade Católica de São Paulo. Doutor em História pela Universidade Federal de Juiz de Fora (UFJF) com estágio de doutoramento no Instituto de Ciências Sociais da Universidade de Lisboa (ICS-UL). Brasileiro, residente em Juiz de Fora (MG). E-mail: pidtanagino@gmail.com 
consequentemente, ao método do materialismo histórico de Karl Marx, cuja noção fundamental de "luta de classes" se fez central ao longo de toda a sua obra dali em diante (KONDER, 1999, 43). Os estudos sobre o judaísmo, o romantismo e o marxismo se fundiram de forma singular e original no pensamento benjaminiano, criando uma crítica ao progressismo na teoria da história que fundiu as imagens utópicas do messianismo judaico às da revolução proletária (LÖWY, 2005, 21).

Sua tese de doutoramento O Conceito de Crítica de Arte no Romantismo Alemão, defendida em 1919 na Universidade de Berna, foi recebida com entusiasmo pelo corpo docente e recomendada para publicação. No entanto, a rejeição de sua tese de livre-docência, Origem do Drama Barroco Alemão, apresentada em 1925 ao Departamento de Estética da Universidade de Frankfurt, representou para o autor a perda de qualquer esperança com relação ao prosseguimento de sua carreira acadêmica nas universidades alemãs, um fato que ajudou a modelar sua trajetória rebelde e marginal no campo intelectual europeu. A tese de livre-docência, publicada em 1928, tornou-se uma das principais fontes para os estudiosos da teoria do estado de exceção em Benjamin, reflexões que tiveram a influência direta do pensamento do jurista alemão Carl Schmitt ${ }^{1}$ em sua obra.

Não obstante sua marginalização acadêmica, Benjamin tornou-se um dos principais colaboradores do "círculo externo" do Instituto Para Pesquisa Social da Universidade de Frankfurt, núcleo intelectual que ficou mais conhecido como "Escola de Frankfurt", o que o tornou uma das principais referências na linha da Teoria Crítica da cultura e da razão capitalistas, ao lado de nomes como Max Horkheimer, Theodor Adorno, Eric Fromm e Herbert Marcuse (KONDER, 1999,

\footnotetext{
${ }^{1}$ Carl Schmitt (1888-1985). Jurista, filósofo político e professor universitário (Universidade de Berlim). Sua habilitação à docência foi conquistada com a dissertação $A$ influência do estado de guerra sobre os procedimentos do processo penal ordinário, defendida no final da Primeira Guerra Mundial. Foi um membro ativo e atuante do Partido Nazista de 1933 até 1945, havendo defendido a queima de livros e os expurgos dos autores judeus e "antialemães", e um defensor público da ditadura de Hitler.

Pesquisador de pós-doutoramento na Universidade de São Paulo (USP) e Doutor em História pela Universidade Federal de Juiz de Fora (UFJF) com estágio de doutoramento na Université Paris IV - Sorbonne. Professor do Mestrado Profissional em Administração Pública (PROFIAP) da UFJF. Brasileiro, residente em Juiz de Fora (MG). E-mail: antonio.gasparetto@gmail.com

Pesquisador em estágio de pós-doutoramento com a Bolsa PPGH-PUCSP/PNPD-CAPES.

Número do Processo: 88887.373072/2019-00. Projeto: 88882.463217/2019-01 - Pontifícia Universidade Católica de São Paulo. Doutor em História pela Universidade Federal de Juiz de Fora (UFJF) com estágio de doutoramento no Instituto de Ciências Sociais da Universidade de Lisboa (ICS-UL). Brasileiro, residente em Juiz de Fora (MG). E-mail: pidtanagino@gmail.com
} 
69-73). Benjamin se tornou mais conhecido pelas pesquisas no campo da cultura, no qual dedicou-se, especialmente, pelos processos de transmissão social dos bens culturais e o papel dos intelectuais na organização da cultura, que o levou às investigações da literatura, tradução, poesia, teatro, artes plásticas, cinema e fotografia, pesquisando a fundo o modernismo, as vanguardas artísticas europeias do início do século $X X$, a nova literatura russa após 1917 e a obra de autores e artistas de diferentes formas de expressão, como Goethe, Nietzsche, Dostoiévski, Hölderlin, Baudelaire, Proust, Kafka, Brecht, Klee, dentre outros (BOLLE, 1986, 10-11). Uma série de estudos que se completam com suas reflexões sobre a infância e a literatura infantil, os brinquedos, a brincadeira, a educação e sua necessária reforma.

Benjamin foi, possivelmente, um dos primeiros críticos a enxergar na leitura dos poemas de Baudelaire (em A Perda do Halo) e na ciência social de Marx (no Manifesto do Partido Comunista) uma intertextualidade dos aspectos centrais da modernidade capitalista na cultura burguesa: a "dessacralização" da vida e a "sacralização" da mercadoria como experiência crucial da arte e do pensamento modernos, e como forma de violência cultural para a dominação das classes trabalhadoras (BERMAN, 1987, 152).

Além de levá-lo ao reconhecimento como crítico literário, seus estudos marxistas sobre a cultura o conduziram a uma de suas mais conhecidas reflexões sobre a teoria da história, em que diz: "Nunca houve um documento da cultura que não fosse simultaneamente um documento da barbárie", em cuja conclusão define o papel do materialista histórico "escovar a história a contrapelo", ou seja, o que o define é a opção pela "história dos vencidos", como afirma em suas célebres teses Sobre o Conceito de História (BENJAMIN, 2012, 244-245), último escrito antes de sua morte.

A morte de Benjamin ainda é envolta em mistério. O escritor foi encontrado sem vida em um quarto de hotel em 27 de setembro de 1940, na cidade de Portbou, Catalunha, quando tentava atravessar a fronteira franco-

Pesquisador de pós-doutoramento na Universidade de São Paulo (USP) e Doutor em História pela Universidade Federal de Juiz de Fora (UFJF) com estágio de doutoramento na Université Paris IV - Sorbonne. Professor do Mestrado Profissional em Administração Pública (PROFIAP) da UFJF. Brasileiro, residente em Juiz de Fora (MG). E-mail: antonio.gasparetto@gmail.com Pesquisador em estágio de pós-doutoramento com a Bolsa PPGH-PUCSP/PNPD-CAPES. Número do Processo: 88887.373072/2019-00. Projeto: 88882.463217/2019-01 - Pontifícia Universidade Católica de São Paulo. Doutor em História pela Universidade Federal de Juiz de Fora (UFJF) com estágio de doutoramento no Instituto de Ciências Sociais da Universidade de Lisboa (ICS-UL). Brasileiro, residente em Juiz de Fora (MG). E-mail: pidtanagino@gmail.com 
espanhola dos Pirineus com um grupo de refugiados, detidos pela polícia local para averiguações. O filósofo havia acabado de conseguir um visto para os Estados Unidos, por intermédio dos colegas Adorno e Horkheimer, que emigraram com o Instituto Para Pesquisa Social para Nova York em 1934. Benjamin teria preferido o suicídio por overdose de morfina a ser entregue pelos franquistas espanhóis às autoridades alemãs para a deportação e a morte em um campo de concentração nazista, um terror fundamentado na sua recente experiência como prisioneiro por três meses em um campo de trabalhos forçados em Nevers, França (WITTE, 2017, 137-143).

\section{Direito e poder: violência dominante e violência pregnante.}

O ensaio Para a Crítica da Violência (BENJAMIN, 2013), publicado em 1921, é até hoje um dos textos de Benjamin mais enigmáticos, equivocadamente interpretados e, ainda assim, dos mais prolíficos. Foi saudado por Carl Schmitt nas correspondências que trocava com Benjamin nessa época e demonstra a aproximação intelectual de ambos (DERRIDA, 2018, 63). O tradutor Ernani Chaves, em nota da edição aqui utilizada, chama a atenção para considerações preliminares que precisam ser feitas logo a partir do título do ensaio, e, por isso, também as trazemos aqui. O conceito de "crítica" (Kritik) foi empregado por Benjamin com o seu sentido kantiano de "delimitação de limites", a partir da etimologia grega do verbo krinein (que significa "separar", "distinguir", "delimitar"), do qual derivam também os termos "critério" e "crise". Benjamin objetivou, portanto, delimitar os vários usos do conceito alemão de Gewalt² (que

\footnotetext{
${ }^{2}$ Conforme a nota da tradução: "O substantivo Gewalt provém do verbo arcaico walten: "imperar", "reinar", "ter poder sobre", hoje empregado quase exclusivamente em contexto religioso. Se o uso primeiro de Gewalt remete a potestas, ao poder político e à dominação - como no substantivo composto Staatgewalt, "autoridade ou poder do Estado" -, o emprego da palavra para designar o excesso de força (vis, em latim) que sempre ameaça acompanhar o exercício do poder, a violência, este se firma no uso cotidiano a partir do século XVI (daí, por exemplo, Vergewaltigung, "estupro"). Por essa razão, Willi Bolle traduziu o título do ensaio "Zur Kritik des Gewalt" como "Crítica da violência - Crítica do poder" [...] e João Barrento, como "Para uma Pesquisador de pós-doutoramento na Universidade de São Paulo (USP) e Doutor em História pela Universidade Federal de Juiz de Fora (UFJF) com estágio de doutoramento na Université Paris IV - Sorbonne. Professor do Mestrado Profissional em Administração Pública (PROFIAP) da UFJF. Brasileiro, residente em Juiz de Fora (MG). E-mail: antonio.gasparetto@gmail.com

Pesquisador em estágio de pós-doutoramento com a Bolsa PPGH-PUCSP/PNPD-CAPES.

Número do Processo: 88887.373072/2019-00. Projeto: 88882.463217/2019-01 - Pontifícia Universidade Católica de São Paulo. Doutor em História pela Universidade Federal de Juiz de Fora (UFJF) com estágio de doutoramento no Instituto de Ciências Sociais da Universidade de Lisboa (ICS-UL). Brasileiro, residente em Juiz de Fora (MG). E-mail: pidtanagino@gmail.com
} 
pode ser traduzido tanto como "violência", quanto como "poder") com a finalidade de apresentar uma dupla reflexão sobre a oposição entre o "poder-comoviolência" do direito e do Estado, e a "violência-como-poder" da greve revolucionária.

Benjamin (2013, 121-122) inicia esse ensaio defendendo que, independentemente das suas causas, a violência só se constitui verdadeiramente enquanto tal quando passa a interferir no núcleo ético das relações sociais, cuja esfera é designada pelos conceitos de direito e de justiça. Desse modo fica estabelecida a relação mais elementar de toda a ordenação do direito, que é aquela entre os fins e os meios para se atingir esses fins, relação a partir da qual surge a pergunta crucial para o autor: "se a violência é em determinados casos meio para fins justos ou injustos". Aqui, a crítica do autor penetra os sedimentos das histórias de violência tanto do direito positivo quanto do direito natural. De acordo com Derrida $(2018,75)$, o conceito de "violência" (“Gewalt") analisado por Benjamin "pertence à ordem simbólica do direito, da política e da moral - de todas as formas de autoridade ou de autorização, ou pelo menos de pretensão à autoridade", e aqui, se debruça menos sobre a violência física que sobre a violência simbólica mencionada.

Conforme Walter Benjamin, o direito natural nunca viu como um problema a utilização de meios violentos para realização de fins considerados justos. Na verdade, seu alicerce filosófico foi que forneceu ao período do Terror Jacobino seu fundamento ideológico. O direito natural vê a violência como parte da natureza, por isso a sua utilização só se torna um problema quando suas finalidades são valoradas como "injustas". Assim, conforme a teoria contratualista do Estado, antes do indivíduo abrir mão do seu poder e cedê-lo ao Estado, "ele exerce de jure todo e qualquer poder que ele de facto tem". Com a

crítica do poder como violência" [...]. De todo modo, o que importa é ressaltar a dupla acepção do termo Gewalt, que indica, em si mesmo, a imbricação entre poder político e violência que constitui o pano de fundo da reflexão de Benjamin". (BENJAMIN, 2013, 121-122).

Pesquisador de pós-doutoramento na Universidade de São Paulo (USP) e Doutor em História pela Universidade Federal de Juiz de Fora (UFJF) com estágio de doutoramento na Université Paris IV - Sorbonne. Professor do Mestrado Profissional em Administração Pública (PROFIAP) da UFJF. Brasileiro, residente em Juiz de Fora (MG). E-mail: antonio.gasparetto@gmail.com

Pesquisador em estágio de pós-doutoramento com a Bolsa PPGH-PUCSP/PNPD-CAPES.

Número do Processo: 88887.373072/2019-00. Projeto: 88882.463217/2019-01 - Pontifícia Universidade Católica de São Paulo. Doutor em História pela Universidade Federal de Juiz de Fora (UFJF) com estágio de doutoramento no Instituto de Ciências Sociais da Universidade de Lisboa (ICS-UL). Brasileiro, residente em Juiz de Fora (MG). E-mail: pidtanagino@gmail.com 
influência crescente da teoria do struggle for life no darwinismo social no final do século XIX, a relação entre essa visão dada à violência pela história natural e a filosofia do direito, de modo que a noção de que "toda a violência que é adequada a fins quase exclusivamente naturais também já é, por isso, conforme ao direito" para a tradição jusnaturalista (BENJAMIN, 2013, 123-124).

Dito de outra forma, o direito institucionalizado seria, essencialmente, "mítico". Ou seja, constituiria a vontade de permanência dos "vencedores", da classe então dominante, no poder. O contexto histórico para o qual se volta Benjamin é a tentativa da revolução alemã de 1918 e a sua repressão pelo aparato jurídico da República de Weimar, comprometido com o Ancien Régime alemão. Com essa interpretação, Benjamin buscou ganhar terreno ante juristas conservadores como Carl Schmitt. (BOLLE, 1986, 12). Portanto, os escritos de Benjamin refletiriam a crise dos modelos europeus de democracia burguesa, liberal e parlamentar e, portanto, o próprio conceito de "direito" na República de Weimar (DERRIDA, 2018, 70).

[...] se o critério que o direito positivo estabelece para a conformidade ao direito da violência só pode ser analisado segundo seu sentido, então a esfera de sua aplicação deve ser criticada segundo seu valor. Para esta crítica, deve-se então encontrar o ponto de vista externo à filosofia do direito positivo, mas também externo ao direito natural. Em que medida apenas a reflexão histórico-filosófica sobre o direito pode fornecer tal ponto de vista vai ficar claro (BENJAMIN, 2013, 125).

Conforme Derrida $(2018,76)$, Benjamin teria identificado que as tradições do direito natural e do direito positivo compartilhariam o mesmo pressuposto dogmático, o de que se podem atingir fins justos por meios injustos. Analisando a legislação europeia de sua época, Benjamin percebe que o interesse do direito em monopolizar a violência com relação aos indivíduos não se explicaria pela intenção de garantir os "fins" declarados do direito, mas antes, seria motivado pela intenção de preservar o próprio direito. Assim, qualquer forma de violência que não se encontra sob controle do direito estabelecido o ameaça, não em

Pesquisador de pós-doutoramento na Universidade de São Paulo (USP) e Doutor em História pela Universidade Federal de Juiz de Fora (UFJF) com estágio de doutoramento na Université Paris IV - Sorbonne. Professor do Mestrado Profissional em Administração Pública (PROFIAP) da UFJF. Brasileiro, residente em Juiz de Fora (MG). E-mail: antonio.gasparetto@gmail.com

Pesquisador em estágio de pós-doutoramento com a Bolsa PPGH-PUCSP/PNPD-CAPES.

Número do Processo: 88887.373072/2019-00. Projeto: 88882.463217/2019-01 - Pontifícia Universidade Católica de São Paulo. Doutor em História pela Universidade Federal de Juiz de Fora (UFJF) com estágio de doutoramento no Instituto de Ciências Sociais da Universidade de Lisboa (ICS-UL). Brasileiro, residente em Juiz de Fora (MG). E-mail: pidtanagino@gmail.com 
razão dos fins que essa violência objetiva, "mas por sua mera existência fora do direito", conclui o autor. Benjamin toma o exemplo do "grande criminoso", sendo a fonte da admiração que lhe é dada pela multidão não um fruto da admiração pelo seu ato em si, mas sim "à violência de que seu ato dá testemunho" como diz Benjamin. Isto é, é finalmente percebida a violência fundadora do direito, reconhecida como ato legítimo de fundação ${ }^{3}$, ainda que na forma de um sentimento fugaz gerado pelo ato do "grande criminoso".

Destarte, Benjamin apresentara uma distinção entre duas "violências", a violência fundadora e a violência conservadora, de um modo que o autor se viu obrigado a admitir que uma não pode ser tão diametralmente oposta à outra, posto que a violência fundadora carece do mesmo instinto de autopreservação que a violência conservadora. E aqui é importante lembrar que o conceito de Gewalt (em que pese a influência da filosofia heideggeriana que foi fundamental neste ponto tanto para Benjamin quanto para Schmitt) significa, além de "violência" fundadora, que destrói o antigo direito e funda um novo, é também "o domínio ou a soberania do poder legal, a autoridade autorizante ou autorizada: a força de lei" (DERRIDA, 2018, 73), um tema benjaminiano que tem recebido cada vez mais atenção dos estudiosos da filosofia do direito, especialmente daqueles que se dedicam aos limites da democracia burguesa e as possibilidades de uma democracia radical ${ }^{4}$.

Como exemplo do aparecimento dessas duas concepções, o autor estuda o caso da greve geral revolucionária, como a que viu na Alemanha durante a revolução de 1918, vencida pela socialdemocracia: "a classe trabalhadora invocará sempre seu direito à greve, mas o Estado chamará este apelo de abuso

\footnotetext{
${ }^{3}$ A Nota do Editor neste trecho também nos é importante: "A temática do grande criminoso e da atração que ele exerce sobre o povo é um tema comum à filosofia do direito (por exemplo, em Hegel, no parágrafo 95 da Filosofia do Direito, embora numa direção contrária à de Benjamin) e à literatura, em particular ao Dostoiévski de Crime e Castigo, livro que Nietzsche tanto admirou e que Benjamin lia na época. Benjamin enxerga nessa atração, um indício da suspeita, mesmo inconsciente, que a 'multidão' experimenta com relação à justiça do direito vigente, portanto, uma suspeita que aludiria à origem violenta do direito". (BENJAMIN, 2013, 127).

${ }^{4}$ Sobre isso, uma boa abordagem pode ser encontrada em Souza (2020).

Pesquisador de pós-doutoramento na Universidade de São Paulo (USP) e Doutor em História pela Universidade Federal de Juiz de Fora (UFJF) com estágio de doutoramento na Université Paris IV - Sorbonne. Professor do Mestrado Profissional em Administração Pública (PROFIAP) da UFJF. Brasileiro, residente em Juiz de Fora (MG). E-mail: antonio.gasparetto@gmail.com

Pesquisador em estágio de pós-doutoramento com a Bolsa PPGH-PUCSP/PNPD-CAPES.

Número do Processo: 88887.373072/2019-00. Projeto: 88882.463217/2019-01 - Pontifícia Universidade Católica de São Paulo. Doutor em História pela Universidade Federal de Juiz de Fora (UFJF) com estágio de doutoramento no Instituto de Ciências Sociais da Universidade de Lisboa (ICS-UL). Brasileiro, residente em Juiz de Fora (MG). E-mail: pidtanagino@gmail.com
} 
(pois o direito de greve não foi pensado "dessa maneira") e promulgará seus decretos de emergência" (BENJAMIN, 2013, 129). Por fim, seguindo essa linha de reflexão, Benjamin conclui que a greve mostra que a violência é capaz de fundamentar e modificar relações de direito, e qualquer objeção a esta hipótese poderia ser refutada ao se considerar o caso da violência da guerra, um dos poderes constituintes mais tradicionais.

Se é permitido deduzir que a violência da guerra, enquanto forma originária e arquetípica, é modelo para toda violência que persegue fins naturais, então é inerente a toda violência desse tipo um caráter de instauração do direito. [Esse conhecimento] explica a tendência do direito moderno, acima mencionada, de retirar, pelo menos do indivíduo enquanto sujeito de direito, qualquer violência, mesmo aquela que se dirige a fins naturais (BENJAMIN, 2013, 131).

Em Para Crítica da Violência, Benjamin buscou demonstrar que o poder político dos parlamentos europeus no Entreguerras, especialmente o parlamento alemão, encontrava-se em decadência por que teriam perdido a consciência histórica das forças revolucionárias que os instituíram, e retomar essas forças era o objetivo político de seus escritos. Afastava-se, portanto, de uma visão pragmática de Realpolitk, preferindo mostrar que as relações de poder sempre trazem de volta a violência do poder constituinte, cuja dimensão simbólica do "poder divino" (waltende Gewalt) continua sendo usurpada pelo Estado (BOLLE, 1986, 11).

A waltende Gewalt, a "violência que reina", seria diferente da violência mítica instauradora do direito, que Benjamin chama "violência arbitrária", e diferente também da violência mantenedora do direito, que ele chama "violência administrada". (BENJAMIN, 2013, 156). Neste ponto fica bem visível o "enxerto de mística neomessiânica judaica sobre um neomarxismo pós-soreliano" a que se refere Derrida $(2018,71)$ sobre o núcleo de significado desse ensaio de Benjamin. As reflexões de Benjamin sobre a historicidade da relação entre violência, poder constituinte e direito adquiriram maior solidez em sua tese de

Pesquisador de pós-doutoramento na Universidade de São Paulo (USP) e Doutor em História pela Universidade Federal de Juiz de Fora (UFJF) com estágio de doutoramento na Université Paris IV - Sorbonne. Professor do Mestrado Profissional em Administração Pública (PROFIAP) da UFJF. Brasileiro, residente em Juiz de Fora (MG). E-mail: antonio.gasparetto@gmail.com

Pesquisador em estágio de pós-doutoramento com a Bolsa PPGH-PUCSP/PNPD-CAPES.

Número do Processo: 88887.373072/2019-00. Projeto: 88882.463217/2019-01 - Pontifícia Universidade Católica de São Paulo. Doutor em História pela Universidade Federal de Juiz de Fora (UFJF) com estágio de doutoramento no Instituto de Ciências Sociais da Universidade de Lisboa (ICS-UL). Brasileiro, residente em Juiz de Fora (MG). E-mail: pidtanagino@gmail.com 
livre-docência e configuram, a partir daí, sua preocupação investigativa sobre o conceito de "estado de exceção", que receberá do autor, já em sua maturidade, uma nova interpretação prenhe de significados.

De acordo com Bolle (1986, 9), as reflexões de Origem do Drama Barroco Alemão (BENJAMIN, 1986), escrito em 1925 e publicado em 1928, nascem da perspectiva benjaminiana de uma "história literária a contrapelo", cujo ponto de partida é a experiência vivida pela geração intelectual do autor após a Primeira Guerra Mundial. Benjamin inquire o legado do humanismo Clássico na República de Weimar. A aura de continuidade histórica com que esse legado era apresentado pela política cultural do governo socialdemocrata de Weimar levou Benjamin a criticá-la com a contraposição de uma outra tradição alemã então recalcada, a do Barroco, na qual "a violência histórica não era camuflada sob teorias estéticas harmoniosas e, sim, ostentada”. A partir dessa pesquisa, Benjamin buscou demonstrar as vinculações entre arte e política, tomando o papel da "alegoria" como a peça-chave de uma "história política da escrita", que leva, em sua abordagem, a um estudo imbricado da história da administração do Estado moderno.

O soberano representa a história. Ele segura em suas mãos 0 acontecimento histórico, como se fosse um cetro. Esse ponto de vista não é privativo do dramaturgo. Ele se funda em certas concepções de direito constitucional. Um novo conceito de soberania se formou no século XVII, numa confrontação final com a doutrina jurídica da Idade Média. O velho problema do tiranicídio tornou-se o ponto focal desse debate. Entre as espécies de tirano distinguidas pela antiga teoria do Estado, a do usurpador figurava entre as mais controvertidas. A Igreja o tinha condenado, mas a questão consistia em decidir de quem poderia partir o sinal para eliminá-lo: do povo, do rei rival, ou exclusivamente da Cúria? A posição da Igreja em nada perdera de sua atualidade, pois num século de guerras religiosas o clero tinha boas razões para manter-se fiel a uma doutrina que Ihe dava armas contra príncipes hostis. O protestantismo recusava as pretensões teocráticas dessa doutrina, [...]; a inviolabilidade absoluta do soberano foi defendida com êxito diante da Cúria. Apesar das diferentes posições assumidas pelos partidos, essa doutrina extrema do poder do Príncipe teve sua origem na Contra-Reforma, e foi no início mais inteligente e mais profunda que sua versão moderna. Ao passo que o conceito moderno de soberania resulta no exercício pelo Príncipe de um poder Pesquisador de pós-doutoramento na Universidade de São Paulo (USP) e Doutor em História pela Universidade Federal de Juiz de Fora (UFJF) com estágio de doutoramento na Université Paris IV - Sorbonne. Professor do Mestrado Profissional em Administração Pública (PROFIAP) da UFJF. Brasileiro, residente em Juiz de Fora (MG). E-mail: antonio.gasparetto@gmail.com

Pesquisador em estágio de pós-doutoramento com a Bolsa PPGH-PUCSP/PNPD-CAPES.

Número do Processo: 88887.373072/2019-00. Projeto: 88882.463217/2019-01 - Pontifícia Universidade Católica de São Paulo. Doutor em História pela Universidade Federal de Juiz de Fora (UFJF) com estágio de doutoramento no Instituto de Ciências Sociais da Universidade de Lisboa (ICS-UL). Brasileiro, residente em Juiz de Fora (MG). E-mail: pidtanagino@gmail.com 
executivo supremo, o do Barroco nasce de uma discussão sobre o estado de exceção, e considera que impedi-lo é a mais importante função do Príncipe. Quem reina já está desde o início destinado a exercer poderes ditatoriais, num estado de exceção, quando este é provocado por guerras, revoltas ou outras catástrofes. Essa atitude é típica da Contra-Reforma. O elemento despótico e mundano, emancipando-se da rica sensibilidade vital da Renascença, propõe o ideal de uma estabilização completa, de uma restauração tanto eclesiástica como estatal, com todas as suas consequências. Uma delas é a exigência de um principado cujo estatuto constitucional seja a garantia de uma comunidade próspera, florescente tanto do ponto de vista militar como científico, artístico e eclesiástico. No pensamento teológico-jurídico, tão característico do século, manifesta-se o efeito de retardamento provocado por uma superexcitação do desejo de transcendência, que está na raiz dos acentos provocativamente mundanos e imanentistas do Barroco. Pois ele está obcecado pela ideia da catástrofe, como antítese ao ideal histórico da Restauração. É sobre essa antítese que se constrói a teoria do estado de exceção. Por isso, para explicar por que desaparece, no século seguinte, "a consciência aguda do significado do estado de exceção, que dominava o direito natural do século XVII, não basta invocar a maior estabilidade política do século XVIII. Se "para Kant, o direito de exceção deixou de ser direito", essa opinião é uma decorrência do seu racionalismo teológico (BENJAMIN, 1984, 88-89).

Aqui já podemos perceber que a influência de Carl Schmitt no pensamento benjaminiano sobre o estado de exceção ${ }^{5}$ foi seminal em múltiplos aspectos. Depois de escrever Origem do Drama Barroco Alemão, Benjamin chegou a enviar uma versão deste escrito a Schmitt, em dezembro de 1930, com uma carta de agradecimento ao jurista alemão por lançar luz às suas pesquisas sobre o exercício do poder soberano e o direito do estado de exceção nos Estados modernos, tomando como sua principal referência o livro Teologia Política, publicado por Schmitt em 1922 (LÖWY, 2005, 84), obra citada três vezes no fragmento supracitado.

O jurista Carl Schmitt, no início dos anos 1920, buscava cristalizar um novo ordenamento de direito na Alemanha após a Primeira Guerra Mundial, onde queria instituir uma tradição jurídica moderna de teoria do Estado "que opõe

\footnotetext{
${ }^{5}$ Ausnahmezustand, ou também Notstand, "estado de necessidade", na doutrina alemã, que possui delineamentos estranhos à outras doutrinas Ocidentais, como a italiana, a francesa e a inglesa. (AGAMBEN, 2004, 15).

Pesquisador de pós-doutoramento na Universidade de São Paulo (USP) e Doutor em História pela Universidade Federal de Juiz de Fora (UFJF) com estágio de doutoramento na Université Paris IV - Sorbonne. Professor do Mestrado Profissional em Administração Pública (PROFIAP) da UFJF. Brasileiro, residente em Juiz de Fora (MG). E-mail: antonio.gasparetto@gmail.com

Pesquisador em estágio de pós-doutoramento com a Bolsa PPGH-PUCSP/PNPD-CAPES.

Número do Processo: 88887.373072/2019-00. Projeto: 88882.463217/2019-01 - Pontifícia Universidade Católica de São Paulo. Doutor em História pela Universidade Federal de Juiz de Fora (UFJF) com estágio de doutoramento no Instituto de Ciências Sociais da Universidade de Lisboa (ICS-UL). Brasileiro, residente em Juiz de Fora (MG). E-mail: pidtanagino@gmail.com
} 
autoridade e liberdade, autoridade e democracia". Em sua origem latina antiga, auctoritas está no fundamento jurídico que dá o poder ao Senado Romano de suspender o direito através do senatus consultum ultimum e a consequente proclamação do iustitium. Auctoritas e potestas, seu conceito opositor, formavam "o sentido original pelo qual o povo romano havia concebido sua vida comunitária", sendo a auctoritas uma prerrogativa do Senado, que dependia diretamente do potestas e imperium que eram poder do povo. Segundo Agamben (2004, 116), Hannah Arendt observou em seu trabalho, Que é autoridade?, que essa autoridade havia praticamente desaparecido no mundo moderno, até seu recrudescimento no período entre as duas guerras mundiais.

A utilização do atual termo "autoridade" transmite, de modo geral, um sentido de "capacidade inata ou adquirida de dar ordens e ser obedecido de forma voluntária". Na origem do conceito de "autoridade" existe um núcleo ético fundado no caráter de responsabilidade que envolve uma relação hierárquica entre o "mandar" e o "obedecer", a qual pressupõe o reconhecimento entre as partes do papel que cada uma ocupa nessa relação, ou seja, Ihe atribuem legitimidade. No pensamento político moderno se tornará dominante a certeza de que "a legitimidade transforma o poder em autoridade" (RESENDE, 2000, 59).

Para Arendt (2012, 615-623), o totalitarismo não se diferencia historicamente em relação a outros regimes pela inovação legislativa, pela filosofia do direito ou pela "revolução" nas suas formas da Lei e da legalidade. A inovação da política totalitária é o apossar-se da prerrogativa de suspender qualquer direito ou precedente jurídico, inclusive as leis criadas pelos seus próprios regimes totalitários, e ainda assim, manter a aparência de um estado de legalidade. A política totalitária se arroga o direito de suspender a lei porque cria, no campo teórico e no imaginário social, uma promessa de "libertar o cumprimento da lei de todo ato ou desejo humano; e promete a justiça na terra porque afirma tornar a humanidade à encarnação da lei". O que pode tornar isso possível é a predominância que a ideologia possui na política totalitária,

Pesquisador de pós-doutoramento na Universidade de São Paulo (USP) e Doutor em História pela Universidade Federal de Juiz de Fora (UFJF) com estágio de doutoramento na Université Paris IV - Sorbonne. Professor do Mestrado Profissional em Administração Pública (PROFIAP) da UFJF. Brasileiro, residente em Juiz de Fora (MG). E-mail: antonio.gasparetto@gmail.com

Pesquisador em estágio de pós-doutoramento com a Bolsa PPGH-PUCSP/PNPD-CAPES.

Número do Processo: 88887.373072/2019-00. Projeto: 88882.463217/2019-01 - Pontifícia Universidade Católica de São Paulo. Doutor em História pela Universidade Federal de Juiz de Fora (UFJF) com estágio de doutoramento no Instituto de Ciências Sociais da Universidade de Lisboa (ICS-UL). Brasileiro, residente em Juiz de Fora (MG). E-mail: pidtanagino@gmail.com 
enquanto um sistema de pensamento impulsionado pela "lei do movimento" histórico, sustentada pela filosofia progressista, que afoga qualquer possibilidade de incoerência ou contradição, eliminando assim a liberdade de pensamento dos indivíduos diante dos fatos, para a única interpretação possível apresentada pela lógica da ideologia. Assim, ideologia e terror constituem, para a filósofa, o caráter realmente inovador que distingue o totalitarismo de outras políticas, como 0 autoritarismo, o conservadorismo, o liberalismo, etc.

De acordo com Agamben $(2004,13)$, diante do avanço do cenário de "guerra civil mundial" que se formou após o início da Primeira Guerra Mundial, "o estado de exceção" tendeu a aparecer cada vez mais como o paradigma de governo dominante na política contemporânea. Esse deslocamento de uma medida provisória e excepcional para uma técnica de governo ameaça transformar radicalmente - e, de fato, já transformou de modo muito perceptível - a estrutura e o sentido da distinção tradicional entre os diversos tipos de constituição. Dessa forma, sugere o autor que "O estado de exceção apresentase, nessa perspectiva, como um patamar de indeterminação entre democracia e absolutismo".

O instituto do estado de exceção é um elemento constitutivo do Estado de Direito. Sua origem estaria na Constituição Revolucionária Francesa de 1792, assumindo no mundo contemporâneo a forma de estado de exceção permanente, deixando assim de ser provisório para assumir forma estatal autônoma. Nesse sentido, diz o autor, "o estado de exceção apresenta-se como a forma legal daquilo que não pode ter forma legal” (AGAMBEN, 2004, 12). Assim ocorreria uma transição do estado de exceção para o Estado de exceção. Por isso, Agamben acaba por concluir que "o paradigma da modernidade é o da exceção permanente ou 'desejada', encontrando sua representação não mais na polis ou no Estado moderno, mas no campo de concentração" (MATOS, 2012, 296-298).

Pesquisador de pós-doutoramento na Universidade de São Paulo (USP) e Doutor em História pela Universidade Federal de Juiz de Fora (UFJF) com estágio de doutoramento na Université Paris IV - Sorbonne. Professor do Mestrado Profissional em Administração Pública (PROFIAP) da UFJF. Brasileiro, residente em Juiz de Fora (MG). E-mail: antonio.gasparetto@gmail.com Pesquisador em estágio de pós-doutoramento com a Bolsa PPGH-PUCSP/PNPD-CAPES. Número do Processo: 88887.373072/2019-00. Projeto: 88882.463217/2019-01 - Pontifícia Universidade Católica de São Paulo. Doutor em História pela Universidade Federal de Juiz de Fora (UFJF) com estágio de doutoramento no Instituto de Ciências Sociais da Universidade de Lisboa (ICS-UL). Brasileiro, residente em Juiz de Fora (MG). E-mail: pidtanagino@gmail.com 
Em uma consideração recebida por muitos leitores hodiernos como intempestiva, Agamben conclui, a partir de seus estudos de Benjamin, que o totalitarismo moderno, isto é, vivido do período Entreguerras até nossos dias, pode ser definido como:

[...] a instauração, por meio do estado de exceção, de uma guerra civil legal que permite a eliminação física não só dos adversários políticos, mas também de categorias inteiras de cidadãos que, por qualquer razão, pareçam não integráveis ao sistema político. Desde então, a criação voluntária de um estado de emergência permanente (ainda que, eventualmente, não declarado no sentido técnico) tornou-se uma das práticas essenciais dos Estados contemporâneos, inclusive dos chamados democráticos. (AGAMBEN, 2004, 13).

O que importa neste caso é o que o filósofo do direito Andityas Matos (2012, 283) chama de "a questão central do soberano". Ou seja, a autoridade capaz de decretar a exceção, diante de determinada circunstância (real ou presumida) que não pôde ser prevista nas normas legais existentes. Uma vez definida - ou autodefinida - a autoridade soberana, o estado de exceção por ela declarado leva a uma concentração de poderes que "desconhece tanto a limitação horizontal, subvertendo a lógica de distribuição de competências entre órgãos e funções estatais, quanto a limitação vertical, desconsiderando as restrições impostas ao Estado no que diz respeito à tutela dos direitos fundamentais dos indivíduos".

Talvez não seria tão descabido supor, a partir dessas colocações, que essa foi precisamente a crítica de Benjamin à filosofia do progresso usada pelas forças conservadoras da socialdemocracia de Weimar, as forças sociais que teriam sido as responsáveis pelo processo de alienação da classe trabalhadora alemã em seu tempo, e que a teria tornado uma vítima mais fácil diante do fascismo alemão. O estudo sobre a evolução do conceito de "soberania" em Origem do Drama Barroco Alemão foi um passo importante nas suas inovações

Pesquisador de pós-doutoramento na Universidade de São Paulo (USP) e Doutor em História pela Universidade Federal de Juiz de Fora (UFJF) com estágio de doutoramento na Université Paris IV - Sorbonne. Professor do Mestrado Profissional em Administração Pública (PROFIAP) da UFJF. Brasileiro, residente em Juiz de Fora (MG). E-mail: antonio.gasparetto@gmail.com Pesquisador em estágio de pós-doutoramento com a Bolsa PPGH-PUCSP/PNPD-CAPES. Número do Processo: 88887.373072/2019-00. Projeto: 88882.463217/2019-01 - Pontifícia Universidade Católica de São Paulo. Doutor em História pela Universidade Federal de Juiz de Fora (UFJF) com estágio de doutoramento no Instituto de Ciências Sociais da Universidade de Lisboa (ICS-UL). Brasileiro, residente em Juiz de Fora (MG). E-mail: pidtanagino@gmail.com 
sobre o conhecimento do instituto do estado de exceção nas ditaduras e democracias contemporâneas.

Na tese VIII Sobre o Conceito de História, encontramos, talvez, o principal motivo para o crescente interesse historiográfico pelas reflexões sobre as plurissignificações que o conceito de "estado de exceção" ganha ao longo da obra de Benjamin. A partir dele, a perspectiva de uma "história do ponto de vista dos vencidos" ganha maior potência. Com a chegada de uma nova guerra e a certeza de que as medidas de exceção se tornariam ainda mais ordinárias e fundamentais para as ditaduras, Benjamin se desnuda dos últimos pudores para falar do que acreditava ser o verdadeiro "estado de exceção" do ponto de vista da história dos oprimidos e da classe trabalhadora. Neste ponto, seu pensamento parece formar um Ouroboros, que nos traz de volta às reflexões de 1921, com uma espécie de retificação histórica, sociológica e política ao ensaio Para a Crítica da Violência, pois, conforme Agamben, "Entre os elementos que tornam difícil uma definição do estado de exceção, encontra-se, certamente, sua estreita relação com a guerra civil, a insurreição e a resistência" (AGAMBEN, 2004, 12):

\begin{abstract}
A tradição dos oprimidos nos ensina que o "estado de exceção" ("Ausnahmezustand") em que vivemos é a regra. Precisamos construir um conceito de história que corresponda a esse ensinamento. Perceberemos, assim, que nossa tarefa é originar um verdadeiro estado de exceção; e com isso nossa posição ficará melhor na luta contra o fascismo. Este se beneficia da circunstância de que seus adversários o enfrentam em nome do progresso, considerado como uma norma histórica. - O assombro com o fato de que os episódios que vivemos no século XX "ainda" sejam possíveis, não é um assombro filosófico. Ele não gera nenhum conhecimento, a não ser o conhecimento de que a concepção de história em que se origina é insustentável. (BENJAMIN, 2012, 245).
\end{abstract}

De acordo com Michael Löwy $(2005,83)$, um dos mais proeminentes intérpretes brasileiros do pensamento de Benjamin, esta tese coloca em confronto duas concepções históricas, um confronto crucial para a compreensão

Pesquisador de pós-doutoramento na Universidade de São Paulo (USP) e Doutor em História pela Universidade Federal de Juiz de Fora (UFJF) com estágio de doutoramento na Université Paris IV - Sorbonne. Professor do Mestrado Profissional em Administração Pública (PROFIAP) da UFJF. Brasileiro, residente em Juiz de Fora (MG). E-mail: antonio.gasparetto@gmail.com

Pesquisador em estágio de pós-doutoramento com a Bolsa PPGH-PUCSP/PNPD-CAPES.

Número do Processo: 88887.373072/2019-00. Projeto: 88882.463217/2019-01 - Pontifícia Universidade Católica de São Paulo. Doutor em História pela Universidade Federal de Juiz de Fora (UFJF) com estágio de doutoramento no Instituto de Ciências Sociais da Universidade de Lisboa (ICS-UL). Brasileiro, residente em Juiz de Fora (MG). E-mail: pidtanagino@gmail.com 
do que o filósofo alemão entendeu como essencial nas discussões sobre o "estado de exceção" tradicional e o que seria um real "estado de exceção" do ponto de vista histórico. De um lado, a doutrina progressista comum à tradição da Esquerda, para a qual o "progresso histórico" delinearia uma evolução linear das sociedades rumo à democracia, à liberdade e à paz; e aquela defendida por Benjamin, que se coloca na posição das classes oprimidas, dos "perdedores" históricos, para a qual a barbárie e a violência dos vencedores tem sido sempre a regra, e não a "exceção".

Na primeira tradição, fala-se em uma "exceção à regra do progresso", tratada como "regressão", "desvio" ou "interregno civilizatório" expresso nas manifestações da violência das classes dominantes, como os fascistas do Entreguerras. Nessa visão equivocada da História não pode haver o thaumázein, o "assombro" que se coloca como o verdadeiro princípio da inquirição filosófica, de acordo com a tradição do pensamento aristotélico. Portanto, não pode gerar conhecimento histórico verdadeiro. Na segunda tradição, manifestações como o fascismo se apresentam apenas como "a expressão mais recente e brutal do 'estado de exceção permanente' que é a história da opressão de classe" ou, dito de outra forma, "Essa visão das coisas permite situar o fascismo na continuidade do cortejo dos vencedores".

Por outro lado, como assevera Löwy $(2005,84)$, essa visão se demonstra limitada ao não dar o devido destaque ao que o fascismo teria trazido como inovação, do ponto de vista histórico, em relação às antigas formas de dominação. Não ressalta, assim, aquilo que, por exemplo, a Escola de Frankfurt chama de "administração total", ou Hannah Arendt, de "totalitarismo", cuja maior expressão se daria pelo campo de concentração e a indústria do extermínio. Não obstante, para Derrida (2018, 64-65), desde 1921, Benjamin possivelmente não pensava em outra coisa a não ser na aterrorizante possibilidade da "Solução Final" levada a cabo pelo regime nazista nos anos seguintes. Por fim, e talvez o que seja mais importante e inovador na tese benjaminiana, o "verdadeiro estado

Pesquisador de pós-doutoramento na Universidade de São Paulo (USP) e Doutor em História pela Universidade Federal de Juiz de Fora (UFJF) com estágio de doutoramento na Université Paris IV - Sorbonne. Professor do Mestrado Profissional em Administração Pública (PROFIAP) da UFJF. Brasileiro, residente em Juiz de Fora (MG). E-mail: antonio.gasparetto@gmail.com

Pesquisador em estágio de pós-doutoramento com a Bolsa PPGH-PUCSP/PNPD-CAPES.

Número do Processo: 88887.373072/2019-00. Projeto: 88882.463217/2019-01 - Pontifícia Universidade Católica de São Paulo. Doutor em História pela Universidade Federal de Juiz de Fora (UFJF) com estágio de doutoramento no Instituto de Ciências Sociais da Universidade de Lisboa (ICS-UL). Brasileiro, residente em Juiz de Fora (MG). E-mail: pidtanagino@gmail.com 
de exceção" a que se refere Benjamin seria a interrupção do histórico cortejo dos vencedores, a emancipação das classes dominadas em uma sociedade sem classes, trazida pela força utópica e messiânica da história de opressão da classe trabalhadora e das minorias perseguidas.

\section{CONCLUSÃO}

A investigação de Benjamin em Para a Crítica da Violência foi formulada a partir da crítica a diferentes tradições do direito positivo e do direito natural, em um contexto histórico no qual versões radicalizadas dos pensamentos de Hegel e Maquiavel fundamentavam a ideologia e a filosofia política de movimentos e regimes totalitários. Essa radicalização atingiu seu paroxismo com a formação de um novo paradigma político, o "paradigma do campo de concentração" que impera do período Entreguerras até nossos dias (AGAMBEN, 2004). Isto é, o paradigma de governo formado na transformação radical do conceito de "estado de exceção" em "Estado de exceção", imposto por militantes partidários, políticos, intelectuais e, especialmente, por juristas, como o fundamento do novo conceito de "soberania" que os regimes totalitaristas procuravam erigir, como foi o caso de Carl Schmitt no nazismo a partir de 1933.

Em Origem do Drama Barroco Alemão, o autor procurou demonstrar como a violência sempre esteve entrelaçada ao exercício e representação do poder na Alemanha e, através do método comparativo, em quase todo mundo Ocidental. A questão do poder soberano em decretar ou revogar o estado de exceção e o papel da "alegoria" barroca no Antigo Regime alemão se colocam na obra do autor como uma crítica ao seu próprio presente.

A percepção desse processo na história política de seu tempo parece ter levado Benjamin a concluir na tese VIII Sobre o Conceito de História, que, se as forças conservadoras, se o totalitarismo, se as classes que sempre oprimiram e subjugaram as classes trabalhadores, se a burguesia e o Capital se armam da prerrogativa de criar e aplicar as leis, o mesmo direito, por razão da força de uma

Pesquisador de pós-doutoramento na Universidade de São Paulo (USP) e Doutor em História pela Universidade Federal de Juiz de Fora (UFJF) com estágio de doutoramento na Université Paris IV - Sorbonne. Professor do Mestrado Profissional em Administração Pública (PROFIAP) da UFJF. Brasileiro, residente em Juiz de Fora (MG). E-mail: antonio.gasparetto@gmail.com Pesquisador em estágio de pós-doutoramento com a Bolsa PPGH-PUCSP/PNPD-CAPES. Número do Processo: 88887.373072/2019-00. Projeto: 88882.463217/2019-01 - Pontifícia Universidade Católica de São Paulo. Doutor em História pela Universidade Federal de Juiz de Fora (UFJF) com estágio de doutoramento no Instituto de Ciências Sociais da Universidade de Lisboa (ICS-UL). Brasileiro, residente em Juiz de Fora (MG). E-mail: pidtanagino@gmail.com 
mudança revolucionária histórica também surge, quando se instala a crise de uma classe dominante e a ascensão de uma classe revolucionária. A violência, aqui, não é cogitada apenas na forma da revolução armada. A greve, o boicote, a desobediência, a crítica, o não-trabalho, etc., todos são formas de violência potencial contra o status quo. Essa seria a brecha histórica sobre a qual as classes oprimidas deveriam depositar todas as suas esperanças messiânicas, todas as suas utopias. Sem medo da aposta de criar um verdadeiro estado de exceção, a partir da perspectiva da história dos vencidos, e usar essa força revolucionária a favor de seu poder constituinte de uma nova realidade social e política.

\section{REFERÊNCIAS}

AGAMBEN, Giorgio. Estado de Exceção. Trad. Iraci D. Poleti. 2ed. São Paulo: Boitempo, 2004.

ARENDT, Hannah. Origens do totalitarismo. Trad. Roberto Raposo. São Paulo: Companhia das Letras, 2012.

BENJAMIN, Walter. Origem do Drama Barroco Alemão. Trad. Sérgio Paulo Rouanet. São Paulo: Brasiliense, 1984.

BENJAMIN, Walter. Para a Crítica da Violência. In _: BENJAMIN, Walter. Escritos sobre mito e linguagem: (1915-1921). Trad. Susana Kampff Lages; Ernani Chaves. 2 ed. São Paulo: Duas Cidades/Editora 34, 2013, pp. 121-156. (Col. Espírito Crítico).

BENJAMIN, Walter. Sobre o Conceito de História. In_ : BENJAMIN, Walter. Magia e Técnica, Arte e Política. Trad. Sérgio Paulo Rouanet. 8 ed. São Paulo: Brasiliense, 2012, (Obras Escolhidas), pp. 241-252.

Pesquisador de pós-doutoramento na Universidade de São Paulo (USP) e Doutor em História pela Universidade Federal de Juiz de Fora (UFJF) com estágio de doutoramento na Université Paris IV - Sorbonne. Professor do Mestrado Profissional em Administração Pública (PROFIAP) da UFJF. Brasileiro, residente em Juiz de Fora (MG). E-mail: antonio.gasparetto@gmail.com Pesquisador em estágio de pós-doutoramento com a Bolsa PPGH-PUCSP/PNPD-CAPES. Número do Processo: 88887.373072/2019-00. Projeto: 88882.463217/2019-01 - Pontifícia Universidade Católica de São Paulo. Doutor em História pela Universidade Federal de Juiz de Fora (UFJF) com estágio de doutoramento no Instituto de Ciências Sociais da Universidade de Lisboa (ICS-UL). Brasileiro, residente em Juiz de Fora (MG). E-mail: pidtanagino@gmail.com 
BERMAN, Marshall. Tudo que é sólido desmancha no ar: a aventura da modernidade. Trad. Carlos Felipe Moisés; Ana Maria L. Ioriatti. São Paulo: Companhia das Letras, 1987.

BOLLE, Willi. Apresentação. In_: BENJAMIN, Walter. Documentos de cultura, documentos de barbárie: escritos escolhidos. Trad. Celeste H. M. Ribeiro de Sousa et. al. São Paulo: Cultrix: Editora da Universidade de São Paulo, 1986, pp. 9-14.

DERRIDA, Jacques. Força de Lei: o "fundamento místico da autoridade". Trad. Leyla Perrone-Moisés. São Paulo: Martins Fontes, 2018.

GAGNEBIN, Jeanne Marie. Apresentação. In_ : BENJAMIN, Walter. Escritos sobre mito e linguagem: (1915-1921). Trad. Susana Kampff Lages; Ernani Chaves. 2 ed. São Paulo: Duas Cidades/Editora 34, 2013, pp. 7-11. (Col. Espírito Crítico).

GASPARETTO JÚNIOR, Antonio \& TANAGINO, Pedro Ivo Dias (Org.). Democracia e estado de exceção: entre o temporário e o permanente. Curitiba: CRV, 2020.

KONDER, Leandro. Walter Benjamin: o marxismo da melancolia. 3 ed. Rio de Janeiro: Civilização Brasileira, 1999.

LÖWY, Michael. Walter Benjamin: aviso de incêndio: uma leitura das teses "Sobre o conceito de história. Trad. Wanda Nogueira Caldeira Brant; Jeanne Marie Gagnebin; Marcos Lutz Müller. São Paulo: Boitempo, 2005.

MATOS, Andytias Soares de Moura C. Nomos Pantokrator: apocalipse, exceção, violência. In_ : Revista Brasileira de Estudos Políticos, Belo Horizonte, n. 105, pp. 277-342, jul./dez. 2012.

MBEMBE, Achille. Necropolítica. 3 ed. São Paulo: N-1 Edições, 2020.

RESENDE, Maria Efigênia L. Autoridade/ Tradição. In: SILVA, Francisco Carlos Teixeira da; MEDEIROS, Sabrina Evangelista; VIANNA, Alexander Martins. (Orgs.). Dicionário crítico do pensamento da direita: ideias, instituições e personagens. Rio de Janeiro: FAPERJ/Mauad, 2000, pp. 59-60.

Pesquisador de pós-doutoramento na Universidade de São Paulo (USP) e Doutor em História pela Universidade Federal de Juiz de Fora (UFJF) com estágio de doutoramento na Université Paris IV - Sorbonne. Professor do Mestrado Profissional em Administração Pública (PROFIAP) da UFJF. Brasileiro, residente em Juiz de Fora (MG). E-mail: antonio.gasparetto@gmail.com Pesquisador em estágio de pós-doutoramento com a Bolsa PPGH-PUCSP/PNPD-CAPES. Número do Processo: 88887.373072/2019-00. Projeto: 88882.463217/2019-01 - Pontifícia Universidade Católica de São Paulo. Doutor em História pela Universidade Federal de Juiz de Fora (UFJF) com estágio de doutoramento no Instituto de Ciências Sociais da Universidade de Lisboa (ICS-UL). Brasileiro, residente em Juiz de Fora (MG). E-mail: pidtanagino@gmail.com 
SOUZA, Joyce Karine de Sá. Desalienar o Poder, Viver o Jogo: uma crítica situacionista ao direito. São Paulo: Max Limonad, 2020.

WITTE, Bernd. Walter Benjamin: uma biografia. Trad. Romero Freitas. Belo Horizonte: Autêntica, 2017.

Pesquisador de pós-doutoramento na Universidade de São Paulo (USP) e Doutor em História pela Universidade Federal de Juiz de Fora (UFJF) com estágio de doutoramento na Université Paris IV - Sorbonne. Professor do Mestrado Profissional em Administração Pública (PROFIAP) da UFJF. Brasileiro, residente em Juiz de Fora (MG). E-mail: antonio.gasparetto@gmail.com Pesquisador em estágio de pós-doutoramento com a Bolsa PPGH-PUCSP/PNPD-CAPES. Número do Processo: 88887.373072/2019-00. Projeto: 88882.463217/2019-01 - Pontifícia Universidade Católica de São Paulo. Doutor em História pela Universidade Federal de Juiz de Fora (UFJF) com estágio de doutoramento no Instituto de Ciências Sociais da Universidade de Lisboa (ICS-UL). Brasileiro, residente em Juiz de Fora (MG). E-mail: pidtanagino@gmail.com 